\title{
Overview of the current role of endovascular and surgical treatment in spinal dural arteriovenous fistulas
}

\author{
Amir R. Dehdashti, M.D., ${ }^{1}$ Leodante B. Da Costa, M.D., ${ }^{2}$ Karel G. TerBrugge, M.D., ${ }^{2}$ \\ Robert A. Willinsky, M.D., ${ }^{2}$ Michael Tymianski, M.D., 1 \\ and M. Christopher Wallace, M.D. ${ }^{1}$
}

${ }^{1}$ Division of Neurosurgery and ${ }^{2}$ Department of Medical Imaging, Toronto Brain Vascular Malformation Study Group, University of Toronto, Canada

\begin{abstract}
Dural arteriovenous fistulas are the most common vascular malformations of the spinal cord. These benign vascular lesions are considered straightforward targets of surgical treatment and possibly endovascular embolization, but the outcome in these cases depends mainly on the extent of clinical dysfunction at the time of the diagnosis. A timely diagnosis is an equally important factor, with early treatment regardless of the type more likely to yield significant improvements in neurological functioning. The outcomes after surgical and endovascular treatment are similar if complete obliteration of the fistulous site is obtained. In the present study, the authors evaluated the current role of each modality in the management of these interesting lesions. (DOI: 10.3171/FOC.2009.26.1.E8)
\end{abstract}

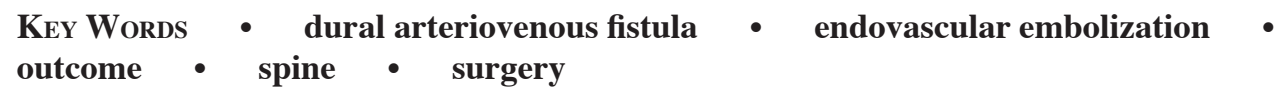

$\mathbf{S}$ PINAL DAVFs are the most common vascular malformations of the spinal cord and its coverings. ${ }^{3}$ Despite their common occurrence, these lesions are not efficiently diagnosed.${ }^{17}$ Although the presence of myelopathy is a distinct key point, the clinical features of a spinal DAVF and noninvasive imaging findings can be very nonspecific. Spinal DAVF is defined by an abnormal connection between the dural branch of a radicular artery and a radicular vein along the inner dural surface near the nerve root. Arterialization of the spinal perimedullary venous plexus results in myelopathy, and rarely, infarction due to venous congestion. ${ }^{2,16}$ The prognosis depends on symptom duration and the extent of ischemia and necrotizing myelopathy that is present at diagnosis. ${ }^{8}$ Timely recognition of the disease and exploration of the area of interest is therefore of paramount importance.

Treatment can be performed efficiently by endovascular or surgical disconnection of the enlarged shunting vein close to the point of its exit from the dura mater., ${ }^{1,21}$ Although successful surgical treatment has yielded significant neurological improvements in many patients, $, 38,40$ endovascular embolization is a less invasive treatment modality that has resulted in a comparable outcome whenever it is technically feasible. ${ }^{14,26,27,31}$

In this overview, we evaluate the role of noninvasive imaging in the diagnosis of spinal DAVF, the implica-

Abbreviations used in this paper: $\mathrm{AVF}=$ arteriovenous fistula; $\mathrm{DAVF}=$ dural AVF tions of surgery and endovascular embolization in the treatment of these lesions, and the outcomes and complications.

\section{Clinical Features}

The clinical presentation of a spinal DAVF almost always includes the signs and symptoms of medullary dysfunction. Hemorrhage - a major presenting sign in cranial DAVFs or premedullary anterior spinal AVFs virtually never occurs in spinal DAVFs, probably because of the slow flow characteristics of these lesions. Involvement of the lower thoracic spinal cord and the medullary conus causes anterior horn nuclei engagement in some cases, and therefore the congestive myelopathy can initially mimic the symptoms of lower motor neuron dysfunction and a peripheral nerve disorder. ${ }^{18,19}$ Venous congestion leading to hypoxia-induced ischemia is accepted as the theory of choice. This is supported by the histopathological findings of an occasional biopsy of the spinal cord $^{16}$ and correlates well with the hypotheses of Foix and Alajouanine ${ }^{13}$ as well as to the findings in a recent description of a necrotizing myelopathy by Matsuo and colleagues. ${ }^{24}$

Previously, published reports have clearly shown that there is a noticeable delay between the first signs of a spinal DAVF and the diagnosis. ${ }^{26,38}$ This delay is particularly important when the significant difference is compared between the rate of neurological disability at 

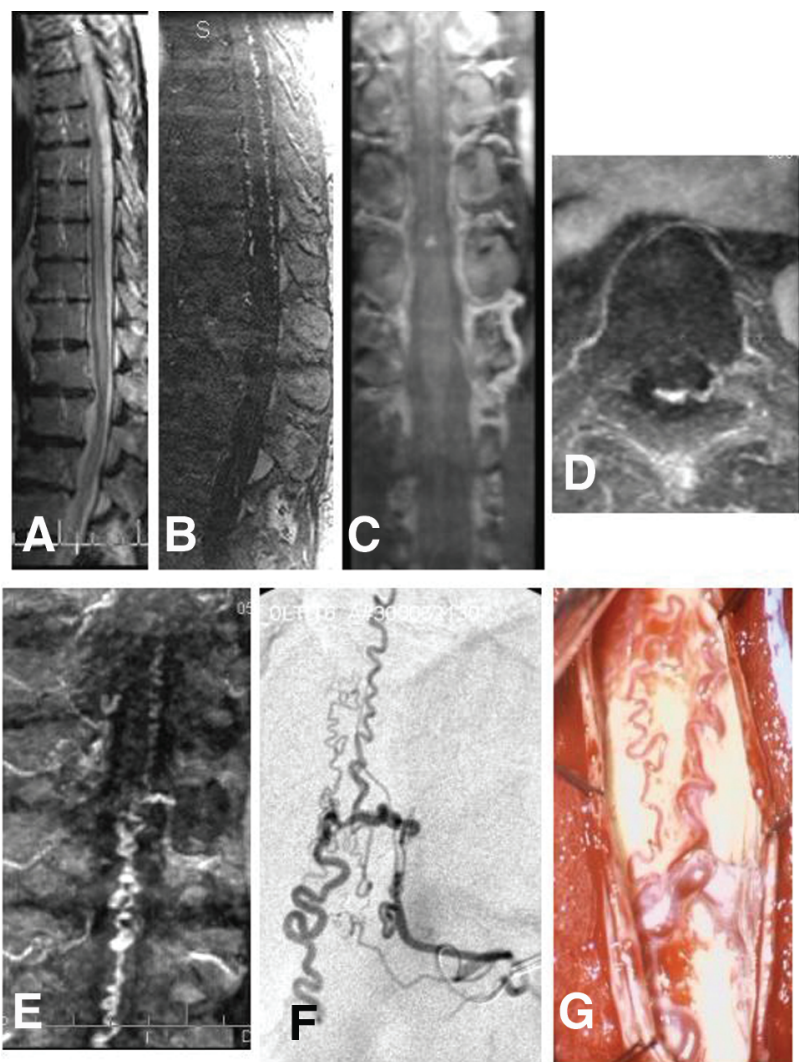

FIG. 1. Sagittal thoracolumbar MR image (A) shows hypersignal intensity suggesting myelopathy in a 62-year-old man with progressive mild paraparesis. The MR ATECO (auto-triggered elliptic centricordered) angiographic views in the sagittal $(B)$ and coronal planes (C and E) suggest unusual dilation of perimedullary vessels and a spinal fistula at the left T-12 level. On axial Gd-enhanced MR angiography (D) the exact level of the fistula at the proximal arterialized vein is shown. Digital subtraction spinal angiogram (F) at the left T-12 level confirms the presence of the fistula, and the fistula is identified after a surgical T11-12 unilateral laminectomy $(\mathrm{G})$.

symptom onset and at presentation at the time of diagnosis. Van Dijk et al. ${ }^{38}$ from our study group reported motor, sensory, and bladder impairment in 55, 47, and 10\%, respectively, of patients with spinal DAVFs at onset. At diagnosis, however, these rates had increased to 96, 90, and $82 \%$, respectively. Narvid and colleagues ${ }^{26}$ have recently reviewed their experience in the treatment of 63 patients with spinal DAVFs. The rates of lower extremity motor and sensory dysfunction increased from the first presentation to the time of diagnosis from 52 and $30 \%$, respectively, to 92 and $65 \%$, respectively; urinary symptoms dramatically worsened from 6 to $83 \%$. These findings confirm that significant impairment of neurological function progresses during the interval between the first presentation and the final diagnosis.

\section{Diagnostic Imaging}

Conventional spinal digital subtraction angiography is still considered the modality of choice to confirm a spinal DAVF diagnosis. Since 1999, Gd-enhanced MR an-
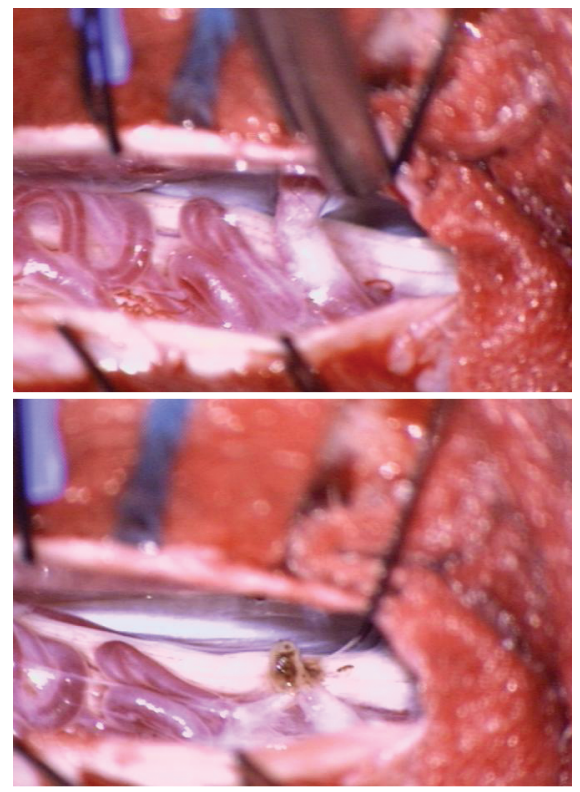

FIG. 2. Upper: Magnified surgical view of the fistula in the inner surface of the dura at the left T-12 nerve root. Lower: Intraoperative view after coagulation of the arterialized vein. The patient made a significant recovery at 16 months follow-up.

giography has proven useful in revealing the level of the fistula before angiography.12 This is performed once there is suspicion of a spinal DAVF based on the spinal MR imaging results (Figs. 1A). In our practice, Gd-enhanced MR angiography has replaced diagnostic angiography, and we currently use it to localize the fistula; angiography is then performed for treatment planning of the fistula. Gadolinium-enhanced MR angiography is a much faster modality than standard multilevel angiography, and allows the diagnostic procedure to be possibly combined with treatment. Multidetector row CT is also considered a useful tool in the diagnosis of spinal DAVFs and perimedullary AVFs. ${ }^{22,23}$

\section{Spinal DAVF Location}

The authors of most case series have shown that spinal DAVFs arise from lower thoracic and lumbar vertebral segmental arteries; the remainder are from the high thoracic region. Fistulas at cervical levels are rare; the highest encountered level in a previously published series was C-7. ${ }^{38}$ There are only 2 reports of patients with cervical DAVFs in the literature: 1 patient presented with radiculopathy ${ }^{20}$ and, remarkably, the other presented without medullary dysfunction. ${ }^{9}$ The rare but possible occurrence of a cervical DAVF requires that the entire length of the spinal dura mater be examined on Gd-enhanced MR and spinal angiography. Furthermore, an intracranial DAVF with spinal drainage should also be suspected when appropriate. ${ }^{6,37}$ Dural AVFs are preponderantly located on the left side. ${ }^{40}$

Another rare but possible scenario is the presence of multiple spinal DAVFs. Double or multiple spinal DAVFs are rare but have been described by several authors, ${ }^{10,28,34}$ and their existence emphasizes the need for detailed an- 


\section{Spinal dural AVF management}

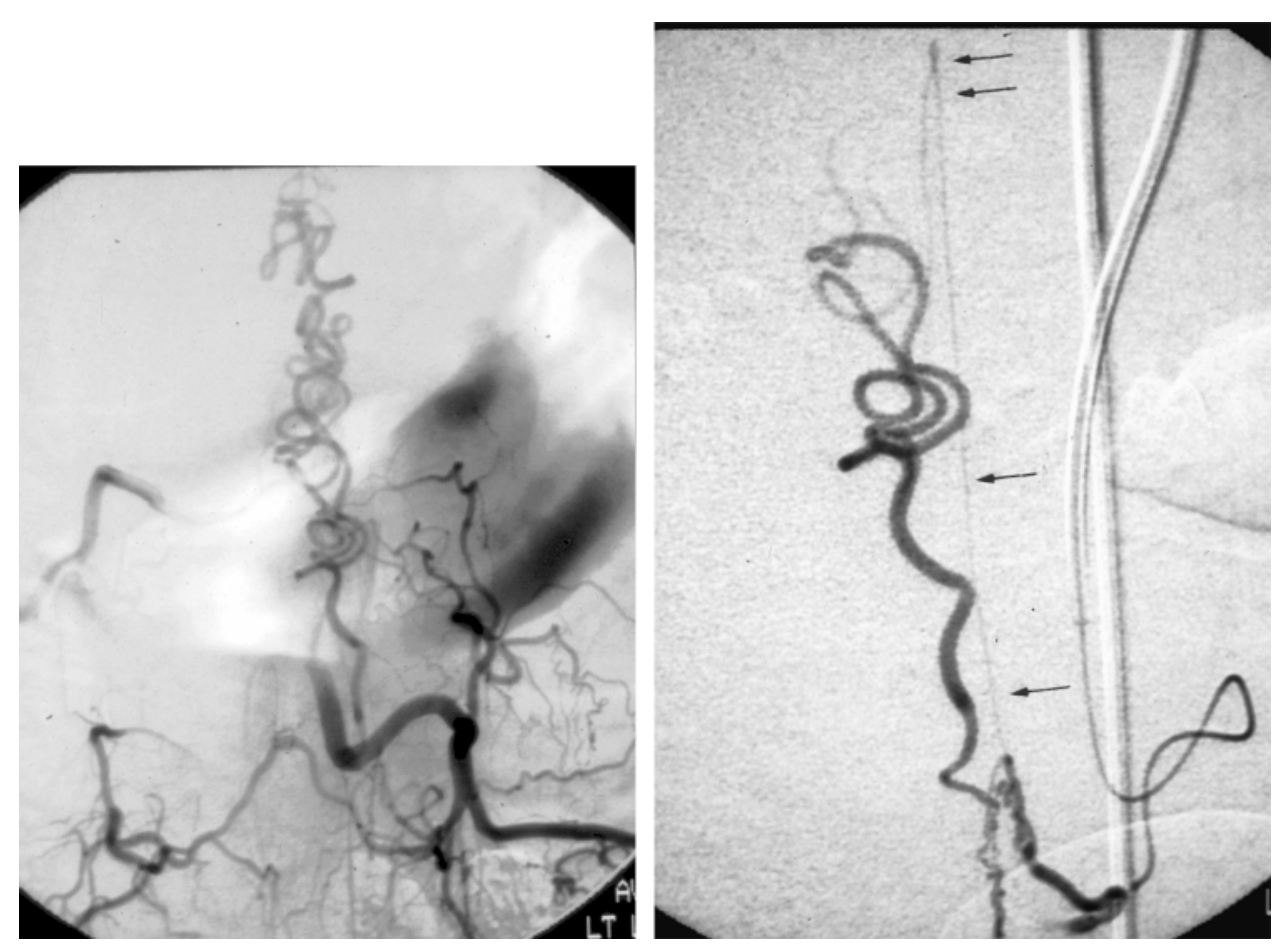

FIG. 3. Left: Left T-11 angiographic exploration showing a spinal DAVF causing progressive gait disturbance in a 71-year-old man. Right: Supraselective injection identifies a common supply to the posterior spinal artery (arrows) and the fistula, making an unsuitable condition for endovascular embolization.

giography in patients in whom spinal DAVF treatment does not result in neurological improvement, or in whom there is subsequent secondary deterioration. At our institution, $2-3 \%$ of patients with DAVFs have more than $1 .{ }^{39}$

\section{Treatment}

\section{Endovascular Treatment}

In our management strategy, endovascular treatment with liquid adhesive material (mixture of $N$-butyl-2-cyanoacrylate and lipiodol) is attempted only if access is deemed possible on the basis of diagnostic imaging, and if a cure is expected after embolization. An additional important factor is the penetration of embolization materials into the proximal vein. Failure of penetration into the proximal vein results in a high rate of fistula persistence or recurrence.

There are several limitations to endovascular treatment. If the spinal DAVF contains a common segmental artery that supplies both the anterior spinal artery (or the posterior spinal artery) and the fistula, the risk in this particular situation should be assessed on diagnostic angiography, and a surgical treatment might be preferable (Fig. 3). A tortuous radicular artery can also limit endovascular access to the fistula (Fig. 4), and excessive endovascular maneuvers to advance the microcatheter to the target point may predict abandoning endovascular treatment in favor of surgery.

Endovascular treatment has been criticized in the past because of its low initial success rate and particularly high recurrence rate of up to $83 \%$ with the use of polyvinyl alcohol. ${ }^{15,25}$ Recent data have suggested a higher success rate and a lower rate of recanalization after endovascular treatment with liquid adhesive embolization. The initial success rate of embolization was $25 \%$ in our patients in a previous study (11 of 44 attempts at embolization were successful), ${ }^{38} 39 \%$ in the Eskandar $\operatorname{series}^{12}$ (9 of 23 attempts), and $69 \%$ (27 of 39 attempts) in the study from Narvid et al. ${ }^{26}$ Depending on whether the penetration of the proximal vein is required, the initial success rate in endovascular series varies from 30 to $90 \% .^{27,32,40}$

In studies that did not rquire proximal vein penetration, recurrence is reportedly as high as $23 \% .{ }^{27}$ In the report by Van Dijk et al. recanalization was not encountered in the 11 of 48 patients who received a cure by embolization alone. There was a $19 \%$ recurrence rate (5 of 27) in the recent series of spinal DAVFs treated endovascularly by Narvid et al. ${ }^{26}$ at the University of California at San Francisco.

The advantages to endovascular therapy include its noninvasiveness, the possibility for immediate angiographic control of treatment, and a shorter hospital stay. ${ }^{26}$ The disadvantages are radiation exposure and the higher rate of recurrences. It is, however, accepted that, once definitive fistula obliteration is achieved, the same clinical evolution will be seen after endovascular embolization as after surgery.

\section{Surgical Treatment}

Symon et al. ${ }^{35}$ and Oldfield and colleagues ${ }^{30}$ have made significant contributions to the understanding and the management of spinal DAVF. Surgical disconnection of the fistula is not a difficult procedure in itself (Fig. 2). 


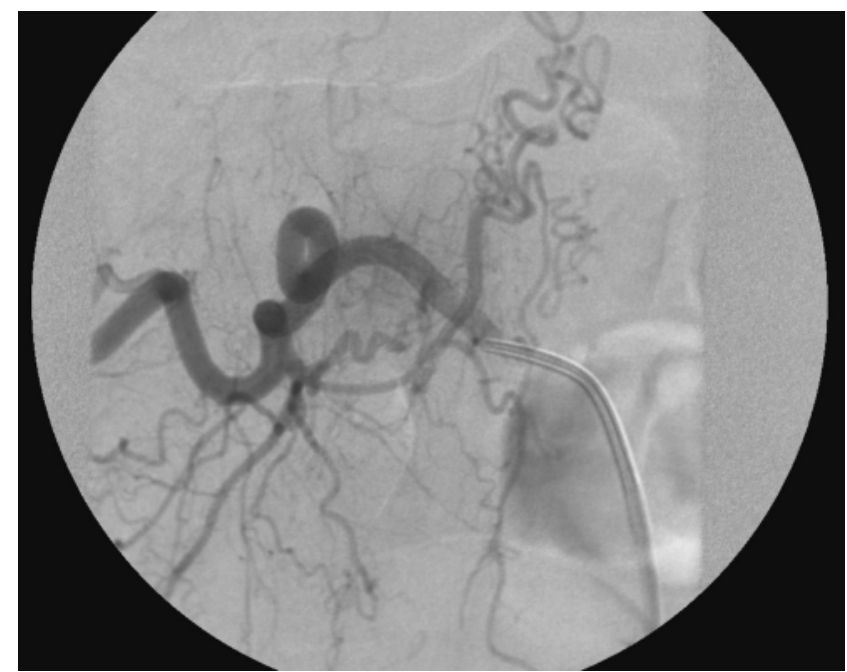

FIG. 4. Right T-11 catheterization depicts a spinal DAVF. The radicular artery is tortuous and an attempt at endovascular embolization failed due to the difficult access.

Correct identification of the spinal level of the fistula is probably more challenging than the actual exposure or disconnection of the fistula itself. Intraoperative fluoroscopy, preoperative localization in the angiographic suite, and possibly neuronavigation can all be used to correctly identify the level of interest. There is no proven superiority, however, of any of these preoperative localization techniques. The authors of a meta-analysis of surgical series estimated an initial success rate of $98 \%$ after surgical obliteration of spinal DAVFs. ${ }^{33}$

\section{Complication Rates}

Complication rates are low for both treatment modalities. In the meta-analysis performed by Steinmetz et al., ${ }^{33}$ the rate was slightly lower after surgery than embolization (1.9 vs $3.7 \%$ ).

Postoperative extension of the thrombosis can cause worsening of neurological symptoms. This is not a direct complication but a rare consequence of the arterialized vein disconnection. This phenomenon has also been reported after endovascular embolization. ${ }^{29}$ The few complications related to microsurgery include pseudomeningocele, instability after laminectomy, and infection.

The most striking feature of endovascular treatment is its relatively high failure rate. On the other hand, inadvertent injection of embolization materials into the perimedullary vessels can cause neurological worsening.

\section{Outcome Evaluation}

Data are insufficient with regard to long-term clinical outcome after endovascular embolization. It is therefore difficult to directly compare the clinical outcome after surgery to the outcome after embolization. The authors of most recent series have adopted a multidisciplinary approach to these lesions. In a recent endovascular series, 26 patients underwent successful embolization of their spinal DAVFs. ${ }^{14}$ At a median follow-up of 21 months, there were 5 patients $(19 \%)$ with recanalization and symptom worsening, and the remaining 21 patients showed marked im- provements from their preoperative neurological status.

When a fistula is cured, the outcome is probably the same regardless of treatment type. The authors of few surgical series have focussed specifically on long-term outcome after surgery. The majority of series with at least 12 months of follow-up show an improvement or stabilization of symptoms after treatment. Surgery has shown to have a low rate of recurrence or persistent fistula. Behrens and Thron ${ }^{5}$ reported on the long-term functional outcome in 21 patients after surgery for spinal DAVFs. At an average of 50 months postoperatively, $67 \%$ of patients demonstrated improvement in motor activity, $71 \%$ had resolution or stabilization in their preoperative pain, and $28 \%$ of male patients demonstrated deterioration in potency. All patients seen at a mean follow-up of 33 months after treatment remained clinically stable or had improved in the van Dijk et al. report. ${ }^{38}$ The median Aminoff scores for gait and bladder function ${ }^{4}$ improved by 1 point in both gait and bladder assessment. Significant improvements in Aminoff scores were also found in both the endovascular and surgical groups in the study by Narvid et al. ${ }^{26}$ at a mean follow-up of 49 months. The study by Tacconi and colleagues $^{36}$ is the only surgical series of 20 patients that has a controversial long-term outcome. At 18-36 months after treatment, surgical interruption of spinal DAVF produced improvement or stabilization of neurological disability in $84 \%$ of patients. However, after a mean followup of 147 months, this amelioration dropped to $35 \%$. This degree of delayed deterioration was not seen in other series. Cenzato et al. ${ }^{8}$ examined the predictors of outcome and found that the type of onset of symptoms (motor deficit) and location of the fistula (lower thoracic) were both considered significant predictors of better functional outcome.

\section{Conclusions}

The current approach to spinal DAVF is multidisciplinary, and prompt diagnosis is the most important factor in its management. Outcome is directly affected by a efficient diagnosis and early treatment. Although surgery has superior overall effectiveness, endovascular embolization may be offered first if safely feasible with the objective of reaching the proximal arterialized vein. We believe that if the fistula is totally obliterated, the outcome is similar regardless of the treatment modality. Surgery or endovascular embolization can both achieve a cure and significant improvement in terms of mobility and functional and neurological outcomes.

\section{References}

1. Afshar JK, Doppman JL, Oldfield EH: Surgical interruption of intradural draining vein as curative treatment of spinal dural arteriovenous fistulas. J Neurosurg 82:196-200, 1995

2. Aminoff MJ, Barnard RO, Logue V: The pathophysiology of spinal vascular malformations. J Neurol Sci 23:255-263, 1974

3. Aminoff MJ, Logue V: Clinical features of spinal vascular malformations. Brain 97:197-210, 1974

4. Aminoff MJ, Logue V: The prognosis of patients with spinal vascular malformations. Brain 97:211-218, 1974 
5. Behrens S, Thron A: Long-term follow-up and outcome in patients treated for spinal dural arteriovenous fistula. J Neurol 246:181-185, 1999

6. Brunereau L, Gobin YP, Meder JF, Cognard C, Tubiana JM, Merland JJ: Intracranial dural arteriovenous fistulas with spinal venous drainage: relation between clinical presentation and angiographic findings. AJNR Am J Neuroradiol 17:1549-1554, 1996

7. Cecchi PC, Musumeci A, Faccioli F, Bricolo A: Surgical treatment of spinal dural arterio-venous fistulae: long-term results and analysis of prognostic factors. Acta Neurochir (Wien) 150:563-570, 2008

8. Cenzato M, Versari P, Righi C, Simionato F, Casali C, Giovanelli M: Spinal dural arteriovenous fistulae: analysis of outcome in relation to pretreatment indicators. Neurosurgery 55:815-823, 2004

9. Chiba S, Nishioka H, Saitoh M, Imai T, Tanabe S, Matsumoto $\mathrm{H}$ : Cervical dural arteriovenous malformation presenting with right-sided occipitalgia: before and after successful treatment by embolization. Headache 34:234-236, 1994

10. El-Serwi A, Maubon A, Vidal J, Chapot R: Double spinal dural arteriovenous fistulas. AJNR Am J Neuroradiol 27:321323, 2006

11. Eskandar EN, Borges LF, Budzik RF Jr, Putman CM, Ogilvy CS: Spinal dural arteriovenous fistulas: experience with endovascular and surgical therapy. J Neurosurg 96:162-167, 2002

12. Farb RI, Kim JK, Willinsky RA, Montanera WJ, terBrugge K, Derbyshire JA, et al: Spinal dural arteriovenous fistula localization with a technique of first-pass gadolinium-enhanced MR angiography: initial experience. Radiology 222:843-850, 2002

13. Foix C, Alajouanine: la myelite necrotique subaigue. Rev Neurol (Paris) 33:1-42, 1926

14. Guillevin R, Vallee JN, Cormier E, Lo D, Dormont D, Chiras J: N-butyl 2-cyanoacrylate embolization of spinal dural arteriovenous fistulae: CT evaluation, technical features, and outcome prognosis in 26 cases. AJNR Am J Neuroradiol 26:929-935, 2005

15. Hall WA, Oldfield EH, Doppman JL: Recanalization of spinal arteriovenous malformations following embolization. J Neurosurg 70:714-720, 1989

16. Hurst RW, Kenyon LC, Lavi E, Raps EC, Marcotte P: Spinal dural arteriovenous fistula: the pathology of venous hypertensive myelopathy. Neurology 45:1309-1313, 1995

17. Jellema K, Tijssen CC, Sluzewski M, van Asbeck FW, Koudstaal PJ, van Gijn J: Spinal dural arteriovenous fistulas-an underdiagnosed disease. A review of patients admitted to the spinal unit of a rehabilitation center. J Neurol 253:159-162, 2006

18. Jellema K, Tijssen CC, van Gijn J: Spinal dural arteriovenous fistulas: a congestive myelopathy that initially mimics a peripheral nerve disorder. Brain 129:3150-3164, 2006

19. Koenig E, Thron A, Schrader V, Dichgans J: Spinal arteriovenous malformations and fistulae: clinical, neuroradiological and neurophysiological findings. J Neurol 236:260-266, 1989

20. Kohno M, Takahashi H, Ide K, Ishijima B, Yamada K, Nemoto $\mathrm{S}$ : A cervical dural arteriovenous fistula in a patient presenting with radiculopathy. Case report. J Neurosurg 84:119-123, 1996

21. Krayenbuhl H, Yaşargil MG, McClintock HG: Treatment of spinal cord vascular malformations by surgical excision. J Neurosurg 30:427-435, 1969

22. Lai PH, Pan HB, Yang CF, Yeh LR, Hsu SS, Lee KW, et al: Multi-detector row computed tomography angiography in diagnosing spinal dural arteriovenous fistula: initial experience. Stroke 36:1562-1564, 2005

23. Lai PH, Weng MJ, Lee KW, Pan HB: Multidetector CT an- giography in diagnosing type I and type IVA spinal vascular malformations. AJNR Am J Neuroradiol 27:813-817, 2006

24. Matsuo K, Kakita A, Ishizu N, Endo K, Watanabe Y, Morita $\mathrm{T}$, et al: Venous congestive myelopathy: three autopsy cases showing a variety of clinicopathologic features. Neuropathology 28:303-308, 2008

25. Morgan MK, Marsh WR: Management of spinal dural arteriovenous malformations. J Neurosurg 70:832-836, 1989

26. Narvid J, Hetts SW, Larsen D, Neuhaus J, Singh TP, McSwain $\mathrm{H}$, et al: Spinal dural arteriovenous fistulae: clinical features and long-term results. Neurosurgery 62:159-167, 2008

27. Niimi Y, Berenstein A, Setton A, Neophytides A: Embolization of spinal dural arteriovenous fistulae: results and followup. Neurosurgery 40:675-683, 1997

28. Niimi Y, Setton A, Berenstein A: Spinal dural arteriovenous fistulae draining to the anterior spinal vein: angiographic diagnosis. Neurosurgery 44:999-1004, 1999

29. Ohta T, Gomi M, Oowaki H, Ishikawa M: Chronic venous congestion following embolization of spinal dural arteriovenous fistula. J Neurosurg Spine 9:186-190, 2008

30. Oldfield EH, Di Chiro G, Quindlen EA, Rieth KG, Doppman JL: Successful treatment of a group of spinal cord arteriovenous malformations by interruption of dural fistula. J Neurosurg 59:1019-1030, 1983

31. Sherif C, Gruber A, Bavinzski G, Standhardt H, Widhalm G, Gibson D, et al: Long-term outcome of a multidisciplinary concept of spinal dural arteriovenous fistulae treatment. Neuroradiology 50:67-74, 2008

32. Song JK, Vinuela F, Gobin YP, Duckwiler GR, Murayama Y, Kureshi I, et al: Surgical and endovascular treatment of spinal dural arteriovenous fistulas: long-term disability assessment and prognostic factors. J Neurosurg 94:199-204, 2001

33. Steinmetz MP, Chow MM, Krishnaney AA, Andrews-Hinders D, Benzel EC, Masaryk TJ, et al: Outcome after the treatment of spinal dural arteriovenous fistulae: a contemporary singleinstitution series and meta-analysis. Neurosurgery 55:77-78, 2004

34. Sugawara T, Kinouchi H, Itoh Y, Mizoi K: Multiple spinal dural arteriovenous fistulas. Acta Neurochir (Wien) 147:423426, 2005

35. Symon L, Kuyama H, Kendall B: Dural arteriovenous malformations of the spine. Clinical features and surgical results in 55 cases. J Neurosurg 60:238-247, 1984

36. Tacconi L, Lopez Izquierdo BC, Symon L: Outcome and prognostic factors in the surgical treatment of spinal dural arteriovenous fistulas. A long-term study. Br J Neurosurg 11:298-305, 1997

37. Tsutsumi S, Yasumoto Y, Ito M, Oishi H, Arai H: Posterior fossa dural arteriovenous fistula as a probable cause of congestive myelopathy. Case report. Neurol Med Chir (Tokyo) 48:171-175, 2008

38. Van Dijk JM, TerBrugge KG, Willinsky RA, Farb RI, Wallace MC: Multidisciplinary management of spinal dural arteriovenous fistulas: clinical presentation and long-term follow-up in 49 patients. Stroke 33:1578-1583, 2002

39. van Dijk JM, TerBrugge KG, Willinsky RA, Wallace MC: Multiplicity of dural arteriovenous fistulas. J Neurosurg 96:76-78, 2002

40. Westphal M, Koch C: Management of spinal dural arteriovenous fistulae using an interdisciplinary neuroradiological/ neurosurgical approach: experience with 47 cases. Neurosurgery 45:451-458, 1999

Manuscript submitted August 26, 2008.

Accepted October 15, 2008.

Address corresponence to: Amir R. Dehdashti, M.D., Division of Neurosurgery, Toronto Western Hospital, 399 Bathurst Street, 4th floor, Toronto, Ontario, Canada. email: amirdehdashti@hotmail. com. 